\title{
Research Article \\ Effects of Ion-Releasing Tooth-Coating Material on Demineralization of Bovine Tooth Enamel
}

\author{
Koji Kawasaki and Masaki Kambara \\ Preventive and Community Dentistry, Osaka Dental University, 8-1 Kuzuha Hanazono, Hirakata, Osaka 573-1121, Japan \\ Correspondence should be addressed to Koji Kawasaki; koji-ks@cc.osaka-dent.ac.jp
}

Received 4 July 2013; Revised 26 October 2013; Accepted 29 October 2013; Published 21 January 2014

Academic Editor: Adriana Modesto Vieira

Copyright ( 2014 K. Kawasaki and M. Kambara. This is an open access article distributed under the Creative Commons Attribution License, which permits unrestricted use, distribution, and reproduction in any medium, provided the original work is properly cited.

\begin{abstract}
We compared the effect of a novel ion-releasing tooth-coating material that contained S-PRG (surface-reaction type prereacted glass-ionomer) filler to that of non-S-PRG filler and nail varnish on the demineralization of bovine enamel subsurface lesions. The demineralization process of bovine enamel was examined using quantitative light-induced fluorescence (QLF) and electron probe microanalyzer (EPMA) measurement. Ion concentrations in demineralizing solution were measured using inductively coupled plasma atomic (ICP) emission spectrometry and an ion electrode. The nail varnish group and the non-S-PRG filler group showed linear demineralization. Although the nail varnish group and the non-S-PRG filler group showed linear demineralization, the S-PRG filler group did not. Further, plane-scanning by EPMA analysis in the S-PRG filler group showed no changes in Ca ion distribution, and $\mathrm{F}$ ions showed peak levels on the surface of enamel specimens. Most ions in the demineralizing solution were present at higher concentrations in the S-PRG filler group than in the other two groups. In conclusion, only the S-PRG fillercontaining tooth-coating material released ions and inhibited demineralization around the coating.
\end{abstract}

\section{Introduction}

In recent years, oral health in developed countries has improved, with the majority of people keeping more sound teeth for longer duration [1-7]. In particular, considerable interest has been directed at detecting caries at early stages, with the development of the International Caries Detection and Assessment System (ICDAS) [8,9] and quantitative lightinduced fluorescence (QLF) method [10, 11]. In current daily dental practice and oral health care programs, the inhibition of initial tooth enamel demineralization and the promotion of remineralization are the most important targets [12-14].

Surface-reaction type prereacted glass-ionomer (S-PRG) filler $[15,16]$ has been reported to have biological efficacy in reducing dental plaque formation $[17,18]$, inhibition of dentin demineralization [19], fluoride release and recharge potential [20], and prevention of demineralization in surrounding orthodontic brackets [21]. These efficacies might be due to the ability of S-PRG filler to release various ion species (fluoride, strontium, aluminum, sodium, etc.) as well as its capacity as an acid buffer [22]. S-PRG filler can therefore be found in various dental products, such as composite resin, root canal sealer, orthodontic resin bonding systems, and denture base resin $[19,23-28]$.

We developed a novel ion-releasing tooth-coating material containing S-PRG filler, which was developed for surfacecoating sound teeth and which consists of a base liquid containing S-PRG filler and an active liquid containing carboxylic and phosphonic adhesive monomers. In clinical practice, the dentist or dental hygienist would mix these two liquids, apply the mixture to the tooth surface with a brush, and polymerize it via light irradiation. To our knowledge, the inhibitory effect of an ion-releasing tooth-coating material that contains S-PRG on the demineralization of tooth enamel has not been reported.

Here, in order to clear this point, we investigated various coating material applications on bovine tooth enamel using the quantitative light-induced fluorescence (QLF) method [29-31] to longitudinally monitor the demineralization process and an electron probe microanalyzer (EPMA) [32] for mineral mapping of demineralized enamel. 


\section{Materials and Methods}

2.1. Preparation of Enamel Specimens. Extracted bovine incisor teeth were used as a source of enamel. Using a core drill to excise bovine enamel specimens ( $5 \mathrm{~mm}$ in diameter), we obtained specimens with an enamel layer thickness of approximately $1.0 \mathrm{~mm}$ and a dentine layer thickness of approximately $2.0 \mathrm{~mm}$. Enamel surfaces were abraded using carbide paper of 600 to 1,500 grit and were then polished with gamma alumina polishing paste (grain diameter, $0.05 \mu \mathrm{m}$ ).

\subsection{Tooth-Coating Materials and Demineralization of Enamel} Specimens. Ten samples from each enamel specimen group were painted with an acid-resistant nonfluorescent varnish (control group), S-PRG filler-containing tooth-coating material (PRG Barrier Coat; Shofu Inc., Kyoto, Japan), or non-S-PRG filler-containing tooth-coating material (Shofu Inc.), leaving an enamel window of approximately $2 \times$ $2 \mathrm{~mm}^{2}$ (coated area was approximately $15 \mathrm{~mm}^{2}$ in size and approximately $10 \mu \mathrm{m}$ in thickness [33]). In separate bottles, specimens were then exposed to $14 \mathrm{~mL}$ of a demineralization solution for 96 hours at $37.0^{\circ} \mathrm{C}$. The demineralization solution contained 0.1 M lactic acid (Kishida Chemical, Osaka, Japan) and $0.2 \mathrm{~g} / \mathrm{L}$ carboxymethyl cellulose sodium salt (Kishida Chemical), was 50\% saturated with hydroxyapatite (Nihon Chemical, Tokyo, Japan), and was adjusted to a pH of 5.0 [34].

2.3. QLF Measurement. Images of specimens containing white spot lesions were acquired with a QLF-Clin system (Inspektor Research Systems BV, Amsterdam, The Netherlands) equipped with QLF.exe evaluation software (version $2.00 \mathrm{~h}$ ) to digitize and quantify the images. Digital images were obtained every $24 \mathrm{~h}$ over a $96 \mathrm{~h}$ period. Specimens were illuminated with violet-blue light $(\lambda=390-430 \mathrm{~nm})$. A CCD camera with a yellow high-pass filter $(\lambda=520 \mathrm{~nm})$ was fixed with a stand in order to provide optimal illumination of the specimen surface. Quantitative results were obtained for the following parameters: mean fluorescence loss over the lesion (\%), area of the lesion $\left(\mathrm{mm}^{2}\right)$, and total fluorescence loss over the lesion $\left(\Delta Q\right.$ in $\left.\% \cdot \mathrm{mm}^{2}\right)$. These parameters were determined using a threshold of $5 \%$ fluorescence radiance loss [35]. $\Delta Q$ is comparable to the total mineral loss from lesions, as measured via longitudinal microradiography [36]. The three different coating materials remained on the tooth enamel surface throughout the $96 \mathrm{~h}$ test period. All analyses of digital images were conducted in the $2 \times 2 \mathrm{~mm}^{2}$ area in the center of the enamel specimens.

2.4. Ion Release from Tooth-Coating Material. After $96 \mathrm{~h}$, demineralized solution was subjected to analysis of ion concentration (B, Al, Ca, P, Si, and $\mathrm{Sr}$ ) using an ICP emission spectrometer (ICPS-8000; Shimadzu, Kyoto, Japan). Analysis of $\mathrm{pH}$ and fluoride ion concentration was performed with an ion electrode ( $\mathrm{pH}$ : Model 9102BNWP and F: Model 9609BN; Orion Research Inc., Boston, MA, USA). TISAB III (Orion Research) was added to the solution in order to obtain a constant background ionic strength for fluoride.

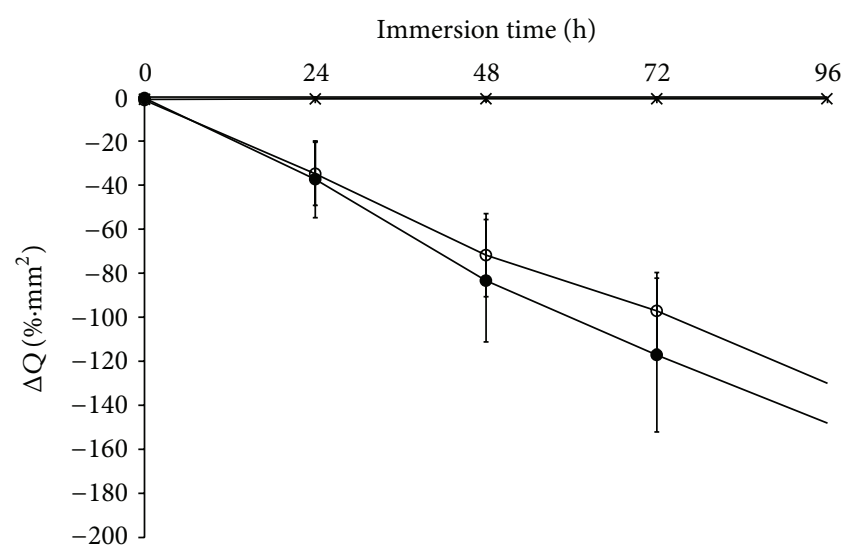

FIgURE 1: Mean $\Delta Q$ for the 3 groups immersed in demineralized solution for $96 \mathrm{~h}$. $\times$ : control group, 0 : non-S-PRG filler group, and O: S-PRG filler group.

2.5. Chemical Composition Analysis of Demineralized Enamel. Demineralized enamel specimens were vertically sectioned with a low-speed diamond cutter and mounted on aluminum stubs. Sectioned specimens were sputter-coated with a $300 \AA$ gold layer using an ion coater (IC-50; Shimadzu) and analyzed using a wavelength-dispersive X-ray spectroscopy electron probe microanalyzer with an image observation function (SEM-EPMA, EPMA1601; Shimadzu). For morphological observation, the subsurface lesions of enamel specimens were analyzed under SEM-EPMA at an accelerating voltage of $15 \mathrm{kV}$. Chemical component bulk analysis and element mapping were carried out using SEM-EPMA for the subsurface area $(60-70 \mu \mathrm{m}$ away from the interface). Distributions of $\mathrm{Ca}$ and $\mathrm{F}$ in the enamel were measured using the element line scan from the interface to the direction of inner enamel with an approximate range of $100 \mu \mathrm{m}$.

2.6. Statistics. Statistical calculations, analysis of variance (ANOVA) followed by Tukey's all-pairwise-comparison test, were performed with software package SPSS version 11.0J for Windows XP (SPSS Inc., Chicago, IL, USA).

\section{Results}

The mean $\Delta Q$ for the three groups (control group, nonS-PRG filler group, and S-PRG filler group), immersed in demineralized solution for 96 hours, is shown in Figure 1. QLF digital images are shown in Figure 2. Mean $\triangle Q$ at $96 \mathrm{~h}$ was $-148.1 \pm 38.9 \% \cdot \mathrm{mm}^{2}$ for the control group, $-130.0 \pm 21.2 \% \cdot \mathrm{mm}^{2}$ for the non-S-PRG filler group, and $-0.8 \pm 0.4 \% \cdot \mathrm{mm}^{2}$ for the S-PRG filler group. The differences between the S-PRG filler and the other two groups were statistically significant $(P<0.001)$. In the $S-P R G$ group, no signs of demineralization were observed in QLF digital images (Figure 2).

The $\mathrm{pH}$ values of the demineralized solution did not change after $96 \mathrm{~h}$ of immersion. Mean ion concentrations in the demineralized solution, as assessed using ICP emission spectrometry, are shown in Table 1. While no significant 


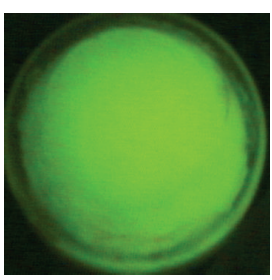

0 hours

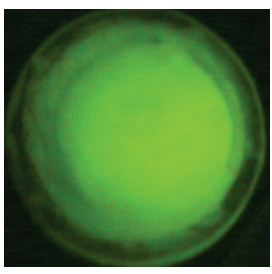

0 hours

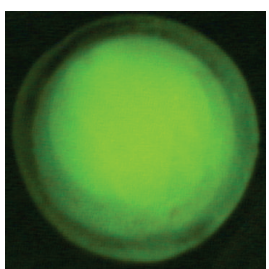

0 hours

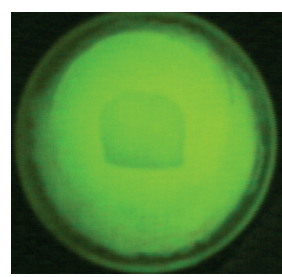

24 hours

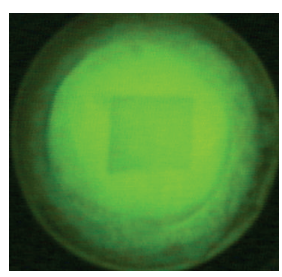

24 hours

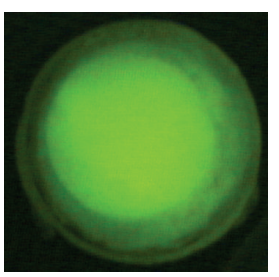

24 hours

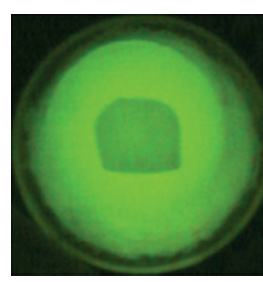

48 hours

(a)

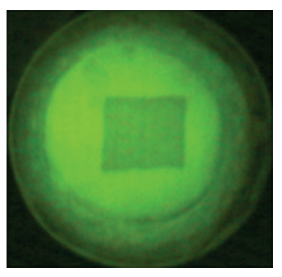

48 hours

(b)

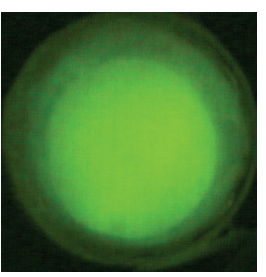

48 hours

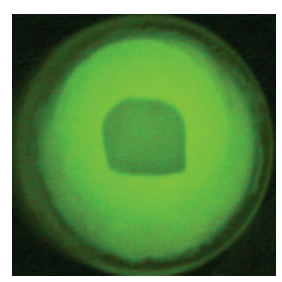

72 hours

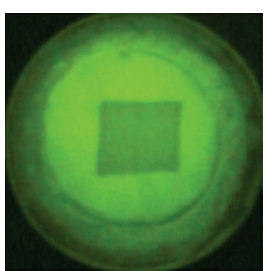

72 hours

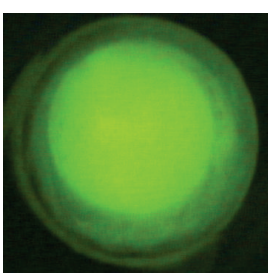

72 hours

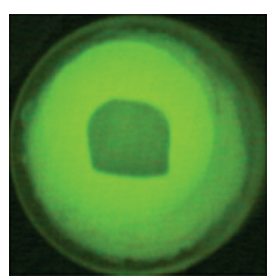

96 hours

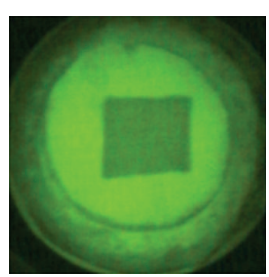

96 hours

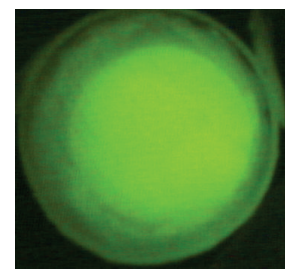

96 hours

(c)

FIGURE 2: Digital images of QLF after the $96 \mathrm{~h}$ demineralizing process. (a) Control group, (b) non-S-PRG filler group, and (c) S-PRG filler group.

TABLE 1: Mean ion concentrations (ppm) in demineralization solution as determined by ICP emission spectrometry.

\begin{tabular}{|c|c|c|c|c|c|c|c|}
\hline & $\mathrm{Al}$ & B & $\mathrm{Ca}$ & $\mathrm{P}$ & $\mathrm{Si}$ & $\mathrm{Sr}$ & $\mathrm{F}$ \\
\hline Control group & $0.23( \pm 0.05)$ & $0.95( \pm 0.09)$ & $164.61( \pm 13.16)$ & $88.20( \pm 1.74)$ & $1.75( \pm 0.21)$ & $0.07( \pm 0.01)$ & $0.00( \pm 0.00)$ \\
\hline Non-S-PRG filler group & $0.18( \pm 0.03)$ & $0.90( \pm 0.11)$ & $172.53( \pm 3.53)$ & $90.98( \pm 1.35)$ & $1.70( \pm 0.09)$ & $0.08( \pm 0.01)$ & $0.00( \pm 0.00)$ \\
\hline S-PRG filler group & $2.91( \pm 0.96)$ & $2.29( \pm 0.48)$ & $162.30( \pm 0.96)$ & $88.01( \pm 1.95)$ & $4.38( \pm 0.98)$ & $9.16( \pm 3.05)$ & $0.34( \pm 0.07)$ \\
\hline
\end{tabular}

differences were noted between the control group and the non-S-PRG filler group, five ions ( $\mathrm{Al}, \mathrm{B}, \mathrm{Si}, \mathrm{Sr}$, and $\mathrm{F}$ ) were present at higher concentrations in the S-PRG filler group than in the other two groups, with the concentration of F ion being particularly elevated. According to the QLF image, the $\mathrm{Ca}$ and $\mathrm{P}$ of tooth enamel were dissolved in the demineralization solution in both the control and non-SPRG filler groups. Concentrations of $\mathrm{Ca}$ and $\mathrm{P}$ in solution may have therefore increased. However, the concentration of the $\mathrm{Ca}$ and $\mathrm{P}$ in the demineralizing solution in both the control and non-S-PRG filler groups showed the approximate value between S-PRG filler group (Table 1). The influence of dissolving tooth enamel appears to be limited.

Plane-scanning analysis via EPMA is shown in Figures 3(a) and 3(b). As the images for the control and non-S-PRG filler group were nearly identical, only the control and S-PRG filler groups are shown. In both groups, a scarcity of $\mathrm{B}, \mathrm{Si}$, and Sr ions was observed in enamel specimens. Results of linescanning analysis for $\mathrm{Ca}$ and $\mathrm{F}$ are shown in Figures 4(a) and 4(b). In the control group, concentrations of Ca ions were lower on the subsurface of enamel specimens than sound enamel, and F ion concentrations were relatively low as well. In the S-PRG group, however, no marked changes were noted in $\mathrm{Ca}$ ion distribution, and $\mathrm{F}$ ions peaked on the surface of enamel specimens.

\section{Discussion}

Mukai et al. [27] reported that an all-in-one adhesive system containing S-PRG filler was able to form protective layers and that it protected dentin against further demineralization in the case of secondary marginal dental caries. Kamijo et al. [20] similarly reported that denture base resins containing S-PRG filler have relatively good fluoride recharge and release capacities, which assist in preventing caries. Most studies have investigated the preventative effects of dentin demineralization after restorative treatment. In our in vitro study, we investigated the inhibitory effects of a tooth-coating 

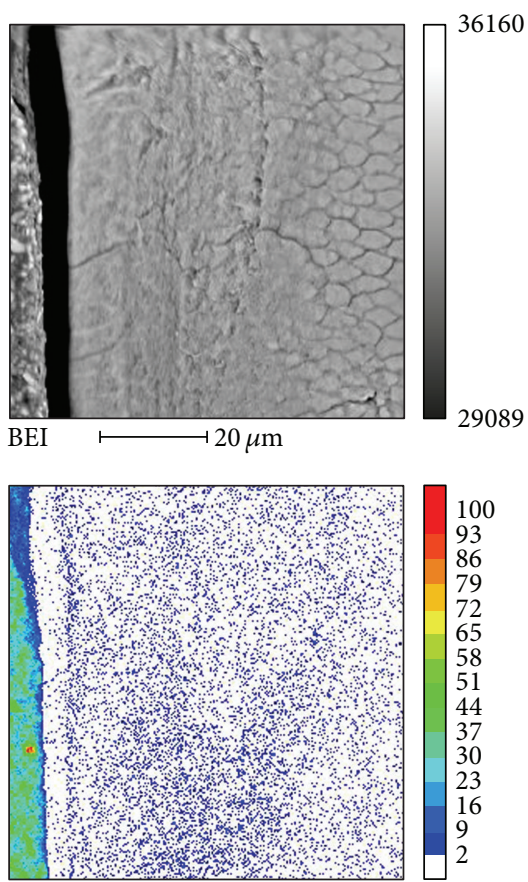

$\mathrm{Si} \mathrm{Ka} \mathrm{\longmapsto} 20 \mu \mathrm{m}$

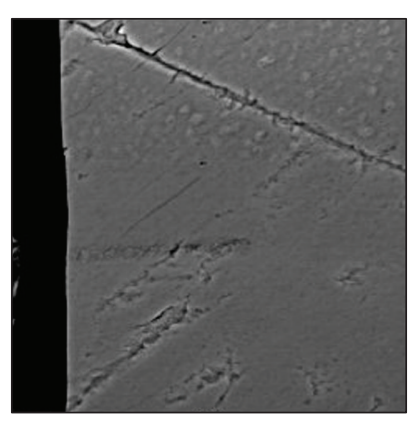

BEI $\longmapsto 20 \mu \mathrm{m}$

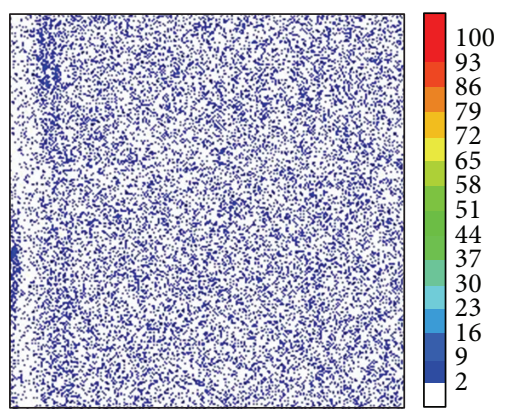

$\mathrm{Si} \mathrm{Ka}$

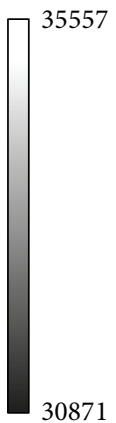

30871

100
93
86
79
72
65
58
51
44
37
30
23
16
9
2
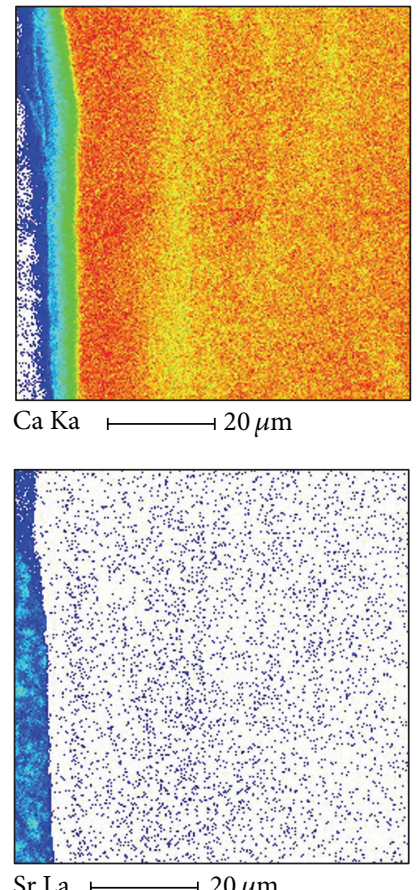

(a)
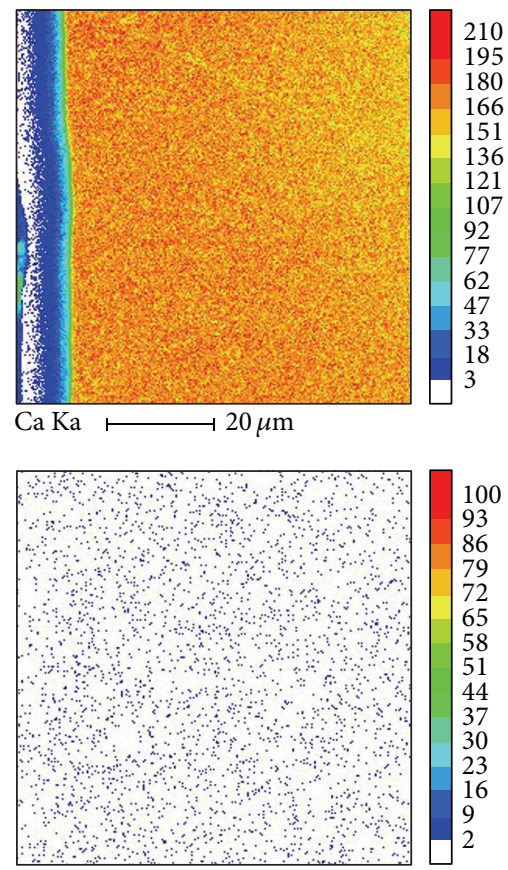

$\mathrm{Sr} \mathrm{La} \longmapsto 20 \mu \mathrm{m}$
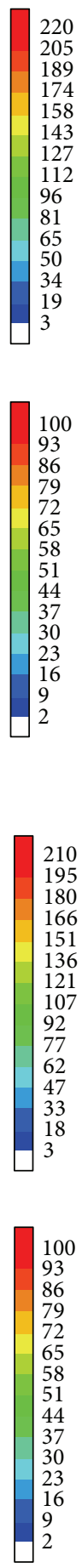

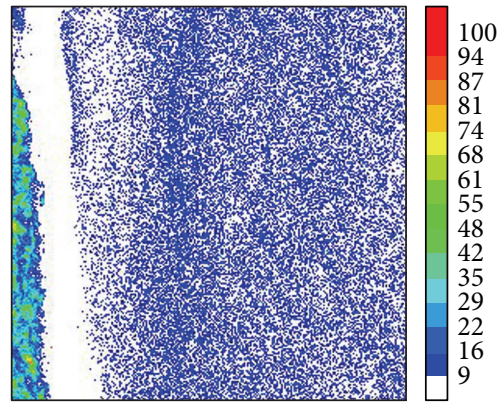

$\mathrm{F} \mathrm{Ka} \longmapsto 20 \mu \mathrm{m}$
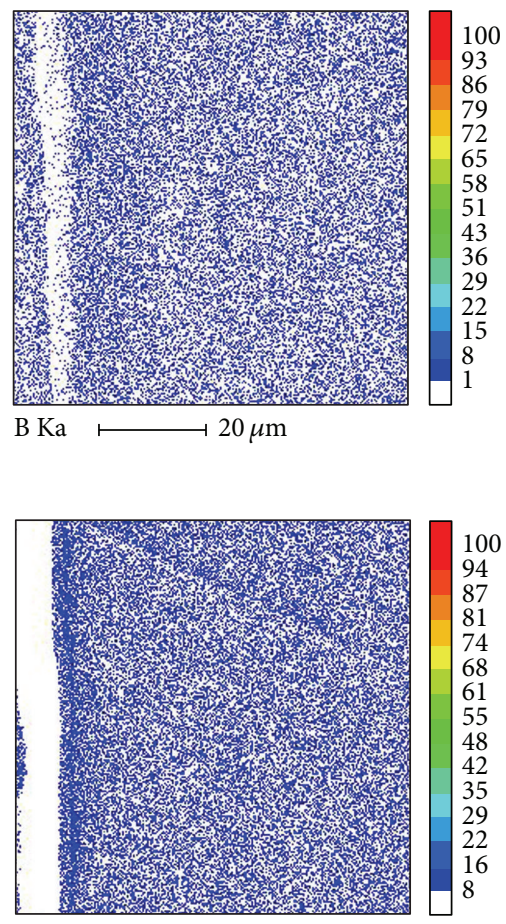

$\mathrm{F} \mathrm{Ka} \longmapsto 20 \mu \mathrm{m}$

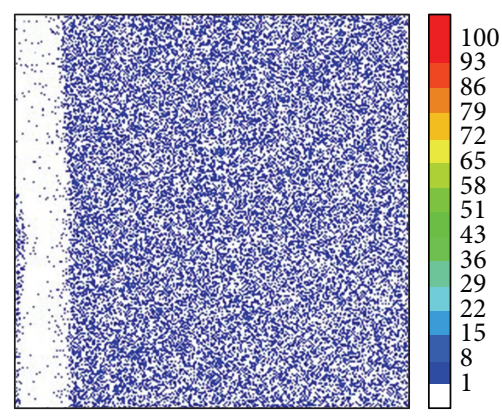

$\mathrm{B} \mathrm{Ka} \longmapsto 20 \mu \mathrm{m}$

(b)

FIGURE 3: Plane-scanning analysis via EPMA. Upper: control; lower: S-PRG filler-containing tooth-coating material. Upper left: SEM image; upper center: calcium; upper right: fluoride; lower left: silica; lower center: strontium; lower right: boron.

material that contained S-PRG filler on the demineralization of bovine tooth enamel. It should be noted that bovine tooth enamel is demineralized more rapidly than human tooth enamel [37]. However, many in vitro studies use bovine tooth [38-40], and it is well known that the human enamel has individual difference. We did not use human tooth enamel specimens given the difficulty in acquiring such specimens.

Based on QLF measurement, tooth-coating material containing S-PRG filler protected the enamel surface against demineralization. In a previous study [41], APF-gel-treated 


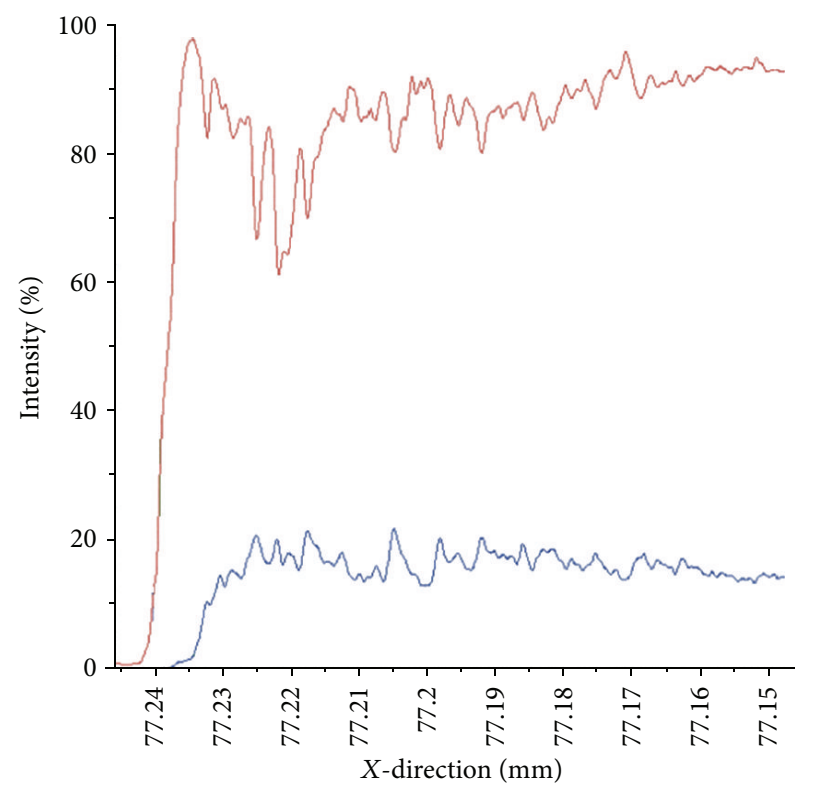

(a)

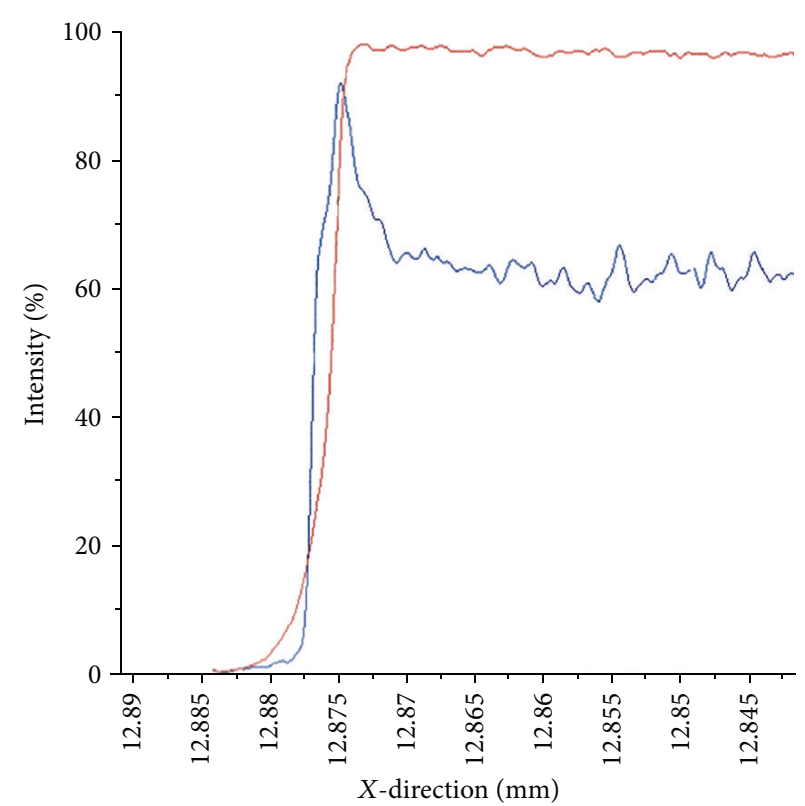

(b)

FIGURE 4: Line scanning analysis by EPMA. Upper: control; lower: S-PRG filler-containing tooth-coating material; red line: Ca; blue line: F.

enamel specimens also showed almost no demineralization. The S-PRG filler-containing coating material blocked demineralization on the coated areas and inhibited demineralization of the surrounding areas. Featherstone et al. [42] reported that the continual presence of low concentrations of fluoride $(0.1-0.5 \mathrm{ppm})$ in whole saliva is critical in the inhibition of demineralization and promotion of remineralization. In the present study, the fluoride concentration in demineralized solution was $0.34 \mathrm{ppm}$, suggesting that the tooth-coating material containing S-PRG filler might release ions and inhibit enamel demineralization.

Table 1 shows the mean ion concentrations in the demineralizing solution. $\mathrm{Al}, \mathrm{B}, \mathrm{Si}, \mathrm{Sr}$, and $\mathrm{F}$ ion concentrations in the demineralized solution of S-PRG filler group were higher than in the other two groups. While $\mathrm{pH}$ values of the demineralizing solution did not change after $96 \mathrm{~h}$ of immersion, the elevated ion concentrations indicate that the demineralizing solution of S-PRG filler group may be induced to behave differently during the demineralization process. Of note, our in vitro study employed a static model to induce demineralization, which may have resulted in an overestimation of the effect of the coating due to a build-up of released ions in the demineralizing solution. The results of this study might not reflect the in vivo conditions in which there is constant salivary clearance.

We also investigated the influence of ions released from S-PRG filler using EPMA as the gold coating was anticipated to have an effect on quantitative analysis via scattering of electrons due to its high atomic number and density. Line-scanning analysis showed that fluoride saturated the sound teeth surface in S-PRG filler-treated specimens. Highdosage APF-gel application on the enamel surface produces a fluoride calcium layer on the tooth surface. Rølla and Øgaard [43] reported that reductions in $\mathrm{pH}$ from 7 to 5 or 4 led to increased solubility of calcium fluoride on the enamel surface into medium solution. This finding suggests that calcium fluoride on the enamel surface acts as a $\mathrm{pH}$ controlled reservoir of fluoride. Figure 4(b) shows that in response to the S-PRG coating material, F ions aggregated on the surface of the enamel specimens. S-PRG filler-containing tooth-coating material also functions as a calcium fluoridelike substance on the tooth surface and may release low concentrations of fluoride ions around the coating material surface.

Most restorative treatments, such as resin fillings, lead to the growth of cariogenic bacteria. Saku et al. [17] reported that the adherence of radiolabeled bacteria to the salivacoated resin surface was significantly lower in S-PRG fillercontaining composite resin than in other filling materials. Yoneda et al. [18] also reported that S-PRG eluate suppresses streptococcal adherence and inhibits the protease and coaggregation activities of Porphyromonas gingivalis. They suggested that the S-PRG filler-containing material reduces dental plaque formation and bacterial adherence. In the present study, ICP emission spectrometry showed that Sr, $\mathrm{B}$, and $\mathrm{Al}$ were present in the demineralized solution. We speculated that these ions inhibit bacterial adhesion on the tooth surface. However, determining the mechanism of this interference will require further investigation.

Despite reports that the frequent use of low concentrations of fluoride agents, such as fluoride-containing toothpaste, is the most beneficial method of preventing demineralization [12], fluoridated dentifrice has failed to fully prevent demineralization [41]. Hausen et al. [44] found no evidence for the effects of fluoride agents on controlling caries in high-risk individuals. The ion-releasing potential of S-PRG filler-containing tooth-coating material may contribute to the prevention of tooth enamel demineralization. 


\section{Conflict of Interests}

While part of the funding and products were provided by Shofu Inc. (Kyoto, Japan), the sponsor of the study had no role in the study design, conduct of the study, data collection, data interpretation, or preparation of the report.

\section{Acknowledgments}

The authors wish to thank Drs. Han Linlin and Takashi Okiji of the Division of Cariology, Operative Dentistry and Endodontics, at Niigata University Graduate School of Medical and Dental Sciences, and Dr. Masayoshi Kobayashi of the Center for Instrumental Analysis at Niigata University. In addition, They are grateful to Mr. Toshiyuki Nakatsuka of Shofu Inc., for his helpful advice regarding EPMA measurement.

\section{References}

[1] A. I. Ismail, J. M. Brodeur, P. Gagnon et al., "Prevalence of noncavitated and cavitated carious lesions in a random sample of 7-9-year-old schoolchildren in Montreal, Quebec," Community Dentistry and Oral Epidemiology, vol. 20, no. 5, pp. 250-255, 1992.

[2] D. C. Clark, H. J. Hann, M. F. Williamson, and J. Berkowitz, "Effects of lifelong consumption of fluoridated water or use of fluoride supplements on dental caries prevalence," Community Dentistry and Oral Epidemiology, vol. 23, no. 1, pp. 20-24, 1995.

[3] T. M. Marthaler, "Changes in dental caries 1953-2003," Caries Research, vol. 38, no. 3, pp. 173-181, 2004.

[4] V. Baelum, W. van Palenstein Helderman, A. Hugoson, R. Yee, and O. Fejerskov, "A global perspective on changes in the burden of caries and periodontitis: implications for dentistry," Journal of Oral Rehabilitation, vol. 34, no. 12, pp. 872-906, 2007.

[5] R. H. Selwitz, A. I. Ismail, and N. B. Pitts, "Dental caries," The Lancet, vol. 369, no. 9555, pp. 51-59, 2007.

[6] P. Cleaton-Jones and P. F. Johannesburg, "Dental caries in children in South Africa and Swaziland: a systematic review 1919-2007," International Dental Journal, vol. 59, no. 6, pp. 363368, 2009.

[7] A. Sheiham and W. Sabbah, "Using universal patterns of caries for planning and evaluating dental care," Caries Research, vol. 44, no. 2, pp. 141-150, 2010.

[8] K. R. Ekstrand, S. Martignon, D. J. N. Ricketts, and V. Qvist, "Detection and activity assessment of primary coronal caries lesions: a methodologic study," Operative Dentistry, vol. 32, no. 3, pp. 225-235, 2007.

[9] A. I. Ismail, W. Sohn, M. Tellez, J. M. Willem, J. Betz, and J. Lepkowski, "Risk indicators for dental caries using the International Caries Detection and Assessment System (ICDAS)," Community Dentistry and Oral Epidemiology, vol. 36, no. 1, pp. 56-68, 2008.

[10] M. B. Diniz, T. Boldieri, J. A. Rodrigues, L. Santos-Pinto, A. Lussi, and R. C. L. Cordeiro, "The performance of conventional and fluorescence-based methods for occlusal caries detection: an in vivo study with histologic validation," Journal of the American Dental Association, vol. 143, no. 4, pp. 339-350, 2012.

[11] L. Karlsson, L.-E. Lindgren, K. Trollsås, B. Angmar-Månsson, and S. Tranaeus, "Effect of supplementary amine fluoride gel in caries-active adolescents. A clinical QLF study," Acta Odontologica Scandinavica, vol. 65, no. 5, pp. 284-291, 2007.

[12] J. D. B. Featherstone, "Prevention and reversal of dental caries: role of low level fluoride," Community Dentistry and Oral Epidemiology, vol. 27, no. 1, pp. 31-40, 1999.

[13] T. J. Lima, C. C. C. Ribeiro, L. M. A. Tenuta, and J. A. Cury, "Low-fluoride dentifrice and caries lesion control in children with different caries experience: a randomized clinical trial," Caries Research, vol. 42, no. 1, pp. 46-50, 2008.

[14] R. P. Ellwood, J. Goma, and I. A. Pretty, "Caries clinical trial methods for the assessment of oral care products in the 21st century," Advances in Dental Research, vol. 24, pp. 32-35, 2012.

[15] Y. Fujimoto, M. Iwasa, R. Murayama, M. Miyazaki, A. Nagafuji, and T. Nakatsuka, "Detection of ions released from S-PRG fillers and their modulation effect," Dental Materials Journal, vol. 29, no. 4, pp. 392-397, 2010.

[16] S. Ito, M. Iijima, M. Hashimoto, N. Tsukamoto, I. Mizoguchi, and T. Saito, "Effects of surface pre-reacted glass-ionomer fillers on mineral induction by phosphoprotein," Journal of Dentistry, vol. 39, no. 1, pp. 72-79, 2011.

[17] S. Saku, H. Kotake, R. J. Scougall-Vilchis et al., "Antibacterial activity of composite resin with glass-ionomer filler particles," Dental Materials Journal, vol. 29, no. 2, pp. 193-198, 2010.

[18] M. Yoneda, N. Suzuki, Y. Masuo et al., "Effect of S-PRG eluate on biofilm formation and enzyme activity of oral bacteria," International Journal of Dentistry, vol. 2012, Article ID 814913, 6 pages, 2012.

[19] Y. Mukai, K. Kamijo, F. Fujino, Y. Hirata, T. Teranaka, and J. M. Ten Cate, "Effect of denture base-resin with prereacted glassionomer filler on dentin demineralization," European Journal of Oral Sciences, vol. 117, no. 6, pp. 750-754, 2009.

[20] K. Kamijo, Y. Mukai, T. Tominaga et al., "Fluoride release and recharge characteristics of denture base resins containing surface pre-reacted glass-ionomer filler," Dental Materials Journal, vol. 28, no. 2, pp. 227-233, 2009.

[21] K. Tomiyama, Y. Mukai, and T. Teranaka, "Acid resistance induced by a new orthodontic bonding system in vitro," Dental Materials Journal, vol. 27, no. 4, pp. 590-597, 2008.

[22] A. Nagafuji, T. Shinno, M. Nakatsuka, M. Deguchi, and N. Negoro, "Ion release and acid buffer capacity of S-PRG filler," Journal of Dental Research, vol. 86, no. 2774, 2007.

[23] L. Han, E. Cv, M. Li et al., "Effect of fluoride mouth rinse on fluoride releasing and recharging from Aesthétic dental materials," Dental Materials Journal, vol. 21, no. 4, pp. 285-295, 2002.

[24] B. A. Matis, M. J. Cochran, T. J. Carlson, C. Guba, and G. J. Eckert, "A three-year clinical evaluation of two dentin bonding agents," Journal of the American Dental Association, vol. 135, no. 4, pp. 451-457, 2004.

[25] Y. Shimada, Y. Seki, Y. Sasafuchi et al., "Biocompatibility of a flowable composite bonded with a self-etching adhesive compared with a glass ionomer cement and a high copper amalgam," Operative Dentistry, vol. 29, no. 1, pp. 23-28, 2004.

[26] V. V. Gordan, C. Shen, R. E. Watson, and I. A. Mjor, "Fouryear clinical evaluation of a self-etching primer and resin-based restorative material," American Journal of Dentistry, vol. 18, no. 1, pp. 45-49, 2005.

[27] Y. Mukai, K. Tomiyama, T. Shiiya, K. Kamijo, F. Fujino, and T. Teranaka, "Formation of inhibition layers with a newly developed fluoride-releasing all-in-one adhesive," Dental Materials Journal, vol. 24, no. 2, pp. 172-177, 2005. 
[28] N. H. F. Wilson, V. V. Gordan, P. A. Brunton, M. A. Wilson, R. J. Crisp, and I. A. Mjör, "Two-centre evaluation of a resin composite/self-etching restorative system: three-year findings," Journal of Adhesive Dentistry, vol. 8, no. 1, pp. 47-51, 2006.

[29] S. al-Khateeb, J. M. Ten Cate, B. Angmar-Månsson et al., "Quantification of formation and remineralization of artificial enamel lesions with a new portable fluorescence device," Advances in Dental Research, vol. 11, no. 4, pp. 502-506, 1997.

[30] R. Heinrich-Weltzien, J. Kühnisch, M. van der Veen, E. de Josselin de Jong, and L. Stößer, "Quantitative light-induced fluorescence (QLF) - a potential method for the dental practitioner," Quintessence International, vol. 34, no. 3, pp. 181-188, 2003.

[31] A. F. Zandoná, E. Santiago, G. Eckert, M. Fontana, M. Ando, and D. T. Zero, "Use of ICDAS combined with quantitative light-induced fluorescence as a caries detection method," Caries Research, vol. 44, no. 3, pp. 317-322, 2010.

[32] L. Han, A. Okamoto, M. Fukushima, and T. Okiji, "Evaluation of a new fluoride-releasing one-step adhesive," Dental Materials Journal, vol. 25, no. 3, pp. 509-515, 2006.

[33] R. Murayama, T. Furuichi, M. Yokokawa et al., "Ultrasonic investigation of the effect of S-PRG filler-containing coating material on bovine tooth demineralization," Dental Materials Journal, vol. 31, pp. 954-959, 2012.

[34] M. Uemura, K. K. Park, G. K. Stookey, and K. Konishi, "Effects of molybdenum on human enamel fluoride uptake and experimental rat dental caries," Archives of Oral Biology, vol. 34, no. 8, pp. 665-668, 1989.

[35] M. H. van der Veen and E. de Josselin de Jong, "Application of quantitative light-induced fluorescence for assessing early caries lesions," in Assessment Oral Health, R. V. Faller, Ed., pp. 144-162, Karger, Basel, Switzerland, 2000.

[36] Z. Emami, S. Al-Khateeb, E. de Josselin de Jong, F. Sundström, K. Trollsås, and B. Angmar-Månsson, "Mineral loss in incipient caries lesions quantified with laser fluorescence and longitudinal microradiography: a methodologic study," Acta Odontologica Scandinavica, vol. 54, no. 1, pp. 8-13, 1996.

[37] B. Øgaard and G. Rølla, "Intra-oral models: comparison of in situ substrates," Journal of Dental Research, vol. 71, pp. 920-923, 1992.

[38] S. M. Machado, D. B. Nascimento, R. C. Silva, S. C. Loretto, and D. Normando, "Evaluation of metallic brackets adhesion after the use of bleaching gels with and without amorphous calcium phosphate (ACP): in vitro study," Dental Press Jounal of Orthodontics, vol. 18, pp. 101-106, 2013.

[39] F. Lippert, A. T. Hara, E. A. Martinez-Mier, and D. T. Zero, "In vitro caries lesion rehardening and enamel fluoride uptake from fluoride varnishes as a function of application mode," American Journal of Dentistry, vol. 26, pp. 81-85, 2013.

[40] J. G. do Amaral, K. T. Sassaki, C. C. Martinhon, and A. C. Delbem, "Effect of low-fluoride dentifrices supplemented with calcium glycerophosphate on enamel demineralization in situ," American Journal of Dentistry, vol. 26, pp. 75-80, 2013.

[41] M. Tajime, K. Kawasaki, and M. Kambara, "Influence of glycoprotein and topical fluoride application on in vitro enamel demineralization," Journal of Public Health Dentistry, vol. 57, pp. 126-135, 2007.

[42] J. D. B. Featherstone, M. M. O'Relly, M. Shariati, and S. Brugler, "Enhancement of remineralization in vitro and in vivo," in Factors Relating to Demineralization and Remineralization of the Tooth, S. A. Leach, Ed., pp. 23-34, IRL Press, Oxford, UK, 1986.
[43] G. Rølla and B. Øgaard, "Studies on the solubility of calcium fluoride in human saliva," in Factors Relating to Demineralization and Remineralization of the Tooth, S. A. Leach, Ed., pp. 45-50, IRL Press, Oxford, UK, 1986.

[44] H. Hausen, S. Kärkkäinen, and L. Seppä, "Application of the high-risk strategy to control dental caries," Community Dentistry and Oral Epidemiology, vol. 28, no. 1, pp. 26-34, 2000. 


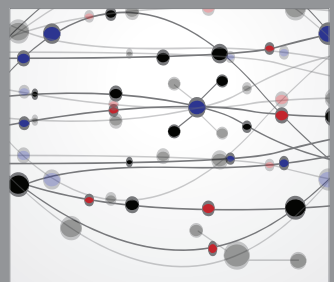

The Scientific World Journal
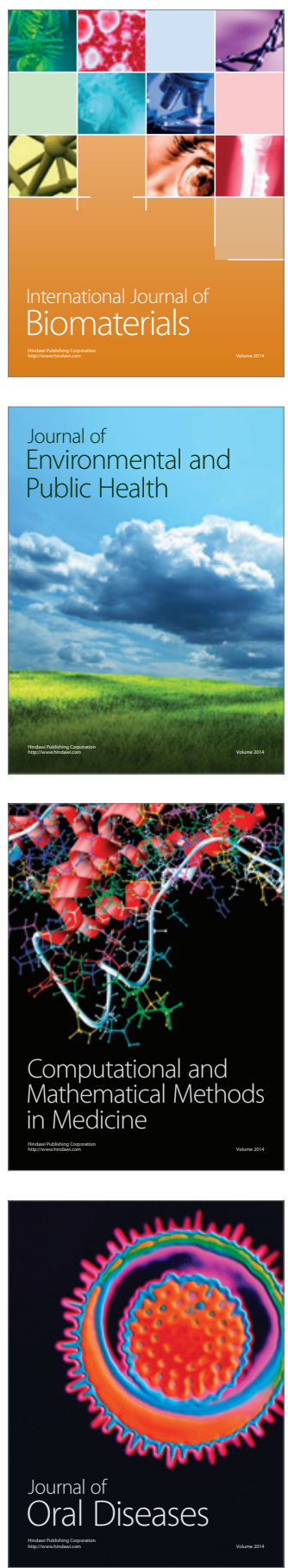
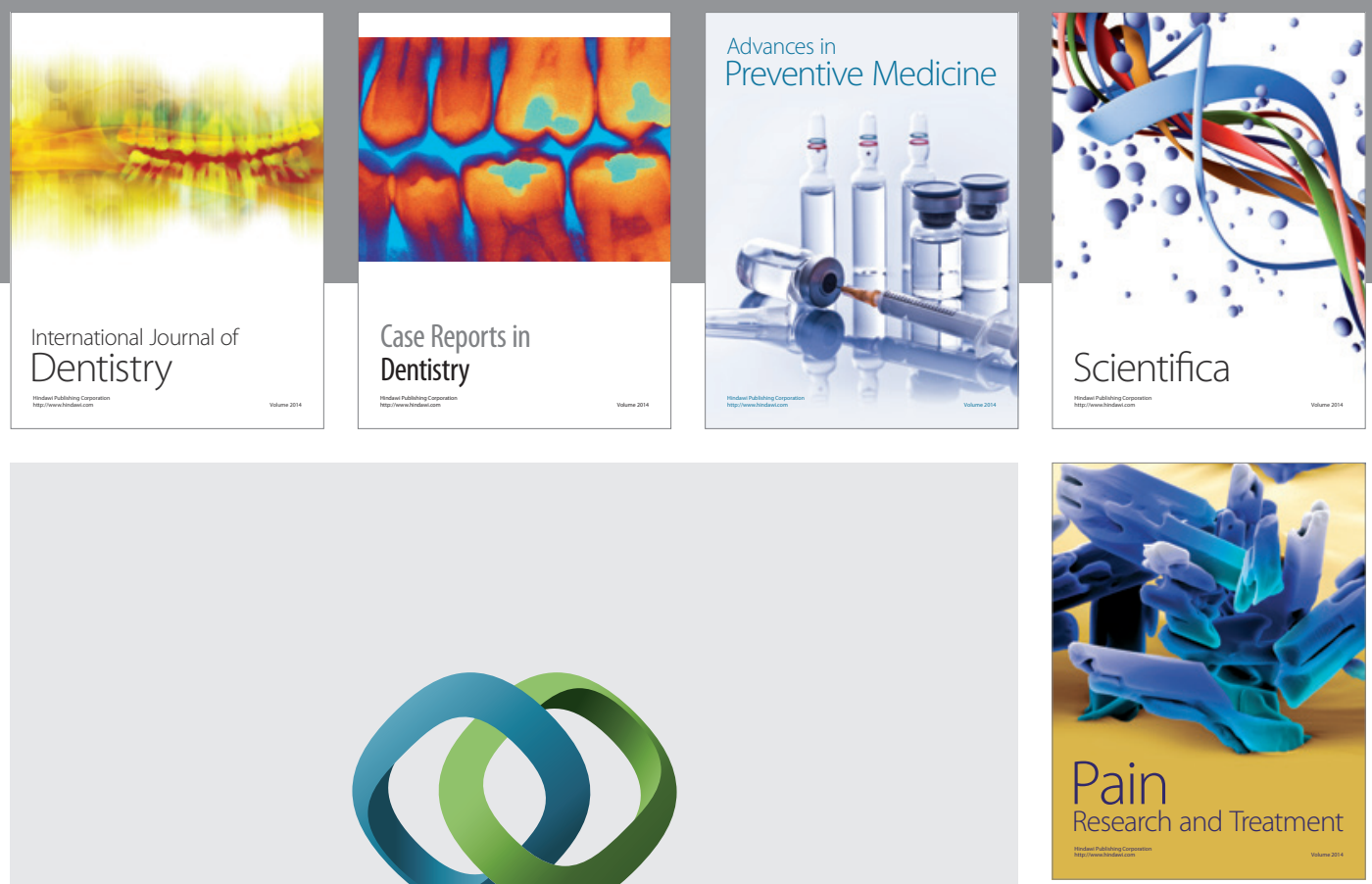

\section{Hindawi}

Submit your manuscripts at

http://www.hindawi.com
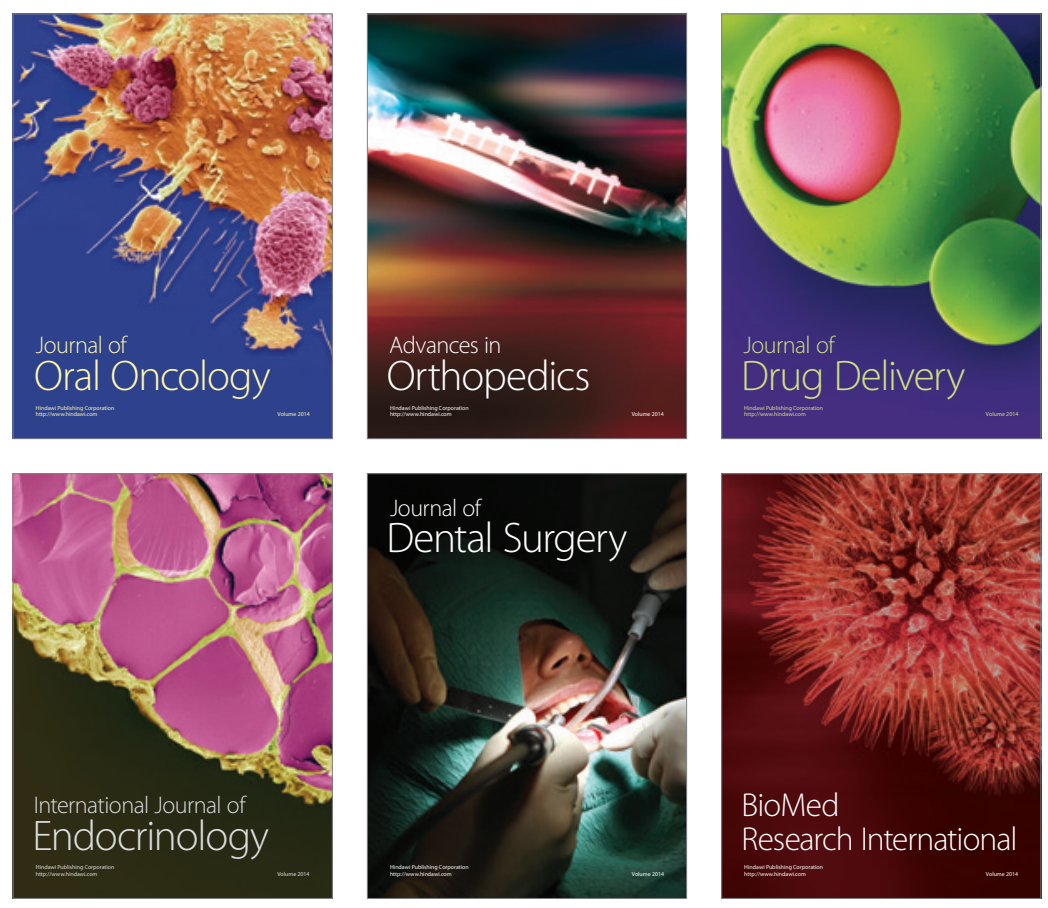

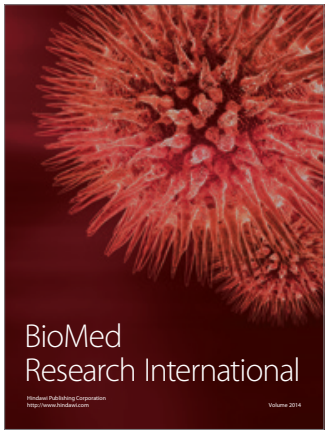

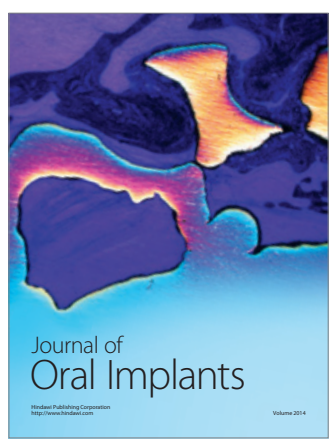
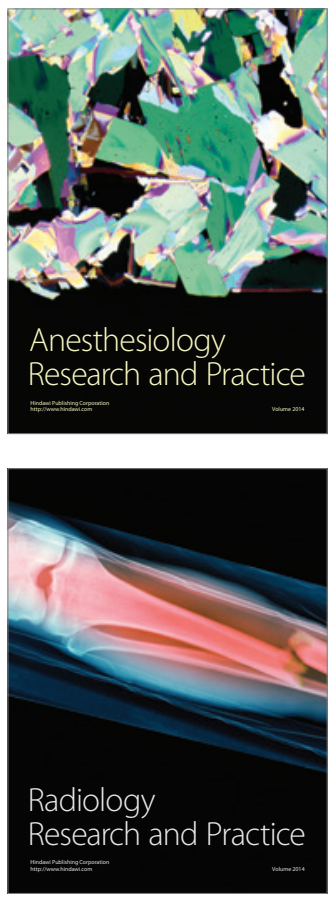